\title{
Analysis of the Lung Pathology and Alveolar Macrophage Function in the Acid Sphingomyelinase-Deficient Mouse Model of Niemann-Pick Disease
}

\author{
Rajwinder Dhami, Xingxuan He, Ronald E. Gordon, and Edward H. Schuchman \\ Departments of Human Genetics (RD, XH, EHS) and Pathology (REG), and Institute for Gene Therapy and Molecular \\ Medicine (EHS), Mount Sinai School of Medicine, New York, New York
}

\begin{abstract}
SUMMARY: Types A and B Niemann-Pick disease (NPD) are lipid storage diseases caused by the deficient activity of the lysosomal enzyme, acid sphingomyelinase (ASM). Type B NPD is associated with progressive pulmonary function decline and frequent respiratory infections. ASM knock-out (ASMKO) mice are available as a model for NPD, but the lung pathology in these mice has not been adequately characterized. This study shows that by 10 weeks of age ASMKO mice have a significantly higher number of cells in their pulmonary airspaces than normal mice, consisting primarily of enlarged and often multinucleated macrophages. These mice also have much higher levels of sphingomyelin in their airspaces at 10 weeks of age, and both cell numbers and sphingomyelin concentrations remain elevated until 26 weeks of age. In these older mice an increased number of neutrophils is also seen. The alveolar cell population in the ASMKO mice produces less superoxide when stimulated, but this can be corrected by providing recombinant ASM to the culture media. Elevated levels of the chemokines macrophage inflammatory protein-2 and macrophage inflammatory protein- $1 \alpha$ were also present in the bronchoalveolar lavage fluid of ASMKO mice, and this correlated with increased production of these chemokines by cultured macrophages and enhanced immunostaining in situ. Also, lung histology showed increased cellularity in the alveolar walls of ASMKO mice, but no evidence of fibrosis. Ultrastructural analysis of the lungs showed that the ASMKO mice have similar pathologic features to human NPD patients, with variable lipid storage evident in type I pneumocytes, endothelial cells, and airway ciliated epithelia. The alveolar macrophage, however, was the most dramatically affected cell type in both mice and humans. These studies indicate that the ASMKO mice can be used as a model to study the lung pathology associated with NPD, and demonstrate that the cellular and biochemical analysis of pulmonary airspaces may be a useful approach to monitoring disease progression and/or treatment. (Lab Invest 2001, 81:987-999).
\end{abstract}

$$
T
$$
ypes A and B Niemann-Pick disease (NPD) are lipid storage diseases resulting from an inherited deficiency of acid sphingomyelinase (ASM; sphingomyelin phosphodiesterase) activity, the lysosomal enzyme responsible for hydrolyzing the phospholipid sphingomyelin to ceramide (Schuchman and Desnick, 2001). Type A NPD is associated with severe neurodegeneration leading to death in early childhood. In contrast, type B NPD patients can survive into adulthood with little or no neurologic involvement, but develop visceral organ complications that often include hepatosplenomegaly and significant respiratory problems including dyspnea and infection (Kovesi et al, 1996; Volk et al, 1972). Respiratory infections and pulmonary function decline are a common cause of morbidity among type B NPD individuals (Lever and Ryder, 1983; Schuchman and Desnick, 2001), and may lead to death in severely affected patients. The

Received April 3, 2001.

This work was supported by NIH Grants 1 ROI HD28607 and 5MOI RR0071.

Address reprint requests to: Dr. Edward H. Schuchman, Department of Human Genetics, Mount Sinai School of Medicine, 1425 Madison Avenue, Rm. 14-20A, New York, NY 10029. E-mail:Edward.Schuchman@mssm.edu lung pathology of type B NPD patients has been routinely characterized by radiography showing evidence of reticulonodular infiltrates (Bouziani et al, 1990; Ferretti et al, 1996; Gerbaux et al, 1971; Gogus et al, 1994; Niggemann et al, 1994). Histologic examination of autopsy lungs has also demonstrated the presence of "foamy cells" (large macrophages with cytoplasmic inclusions) in the alveolar spaces (reviewed in Minai et al, 2000).

Mouse models of NPD have previously been described (Horinouchi et al, 1995; Otterbach and Stoffel, 1995) in which the gene for ASM has been disrupted by embryonic stem cell gene targeting (ASM knockout [ASMKO] mice). Symptoms similar to those in types A and B NPD patients, including neurodegeneration, foamy cell infiltration of reticuloendothelial organs, shortened lifespan, and failure to thrive, have been documented in these mice. The ultrastructure of the ASMKO mouse lungs has previously been described (Kuemmel et al, 1997), but further characterization to demonstrate similarity to the human disease or shed light on the mechanism of pulmonary pathogenesis is lacking.

We therefore undertook a systematic examination of the pulmonary pathology in the ASMKO mice with the 
objective of gaining a more thorough understanding of the pulmonary disease pathogenesis in NPD and of investigating potential clinical, pathological, and/or biochemical parameters by which to monitor the pulmonary disease progression and treatment. We used a simple bronchoalveolar lavage (BAL) technique to follow the progression of lung pathology in these mice and also investigated the functional capacity of their lung inflammatory cells. Histologic and ultrastructural analysis of human and murine NPD lungs was combined with the bronchoalveolar lavage fluid (BALF) cell profiles and biochemical analysis to generate a more thorough picture of the lung pathology in ASMKO mice. The potential significance of our observations with respect to monitoring NPD disease progression and the efficacy of future treatment strategies is discussed.

\section{Results}

\section{Lung Histology}

Low magnification light microscopy revealed few differences between lavaged normal and ASMKO 24week-old mouse lungs with respect to the overall lung architecture (Fig. 1, A and C, respectively). However, despite the fact that the lungs had been lavaged, foamy cells remained in the airspaces and inflammatory cells could be seen in the microvasculature of the ASMKO mice (Fig. 1C, upper right). At higher magnification these foamy macrophages were easily apparent in the pulmonary airspaces (arrowhead) and in the alveolar walls (arrows) of the ASMKO lungs (Fig. 1D) compared with normal mice (Fig. 1B). Lung sections from 4-week-old ASMKO mice were similar, but with fewer cells in the airspaces and pulmonary interstitium (data not shown). Also, peribronchial edema with some cellular infiltrate was sometimes apparent in the 24- to 28-week-old ASMKO group (not seen in these photomicrographs), but no signs of fibrosis were evident.

\section{BALF Cells}

At 4 weeks of age there was no difference in the total number of cells in the BALF from the $(-/-),(+/-)$, and $(+/+)$ mice (Fig. 2). By 10 weeks of age, however, the $(-/-)$ mice had a significantly higher number of cells in
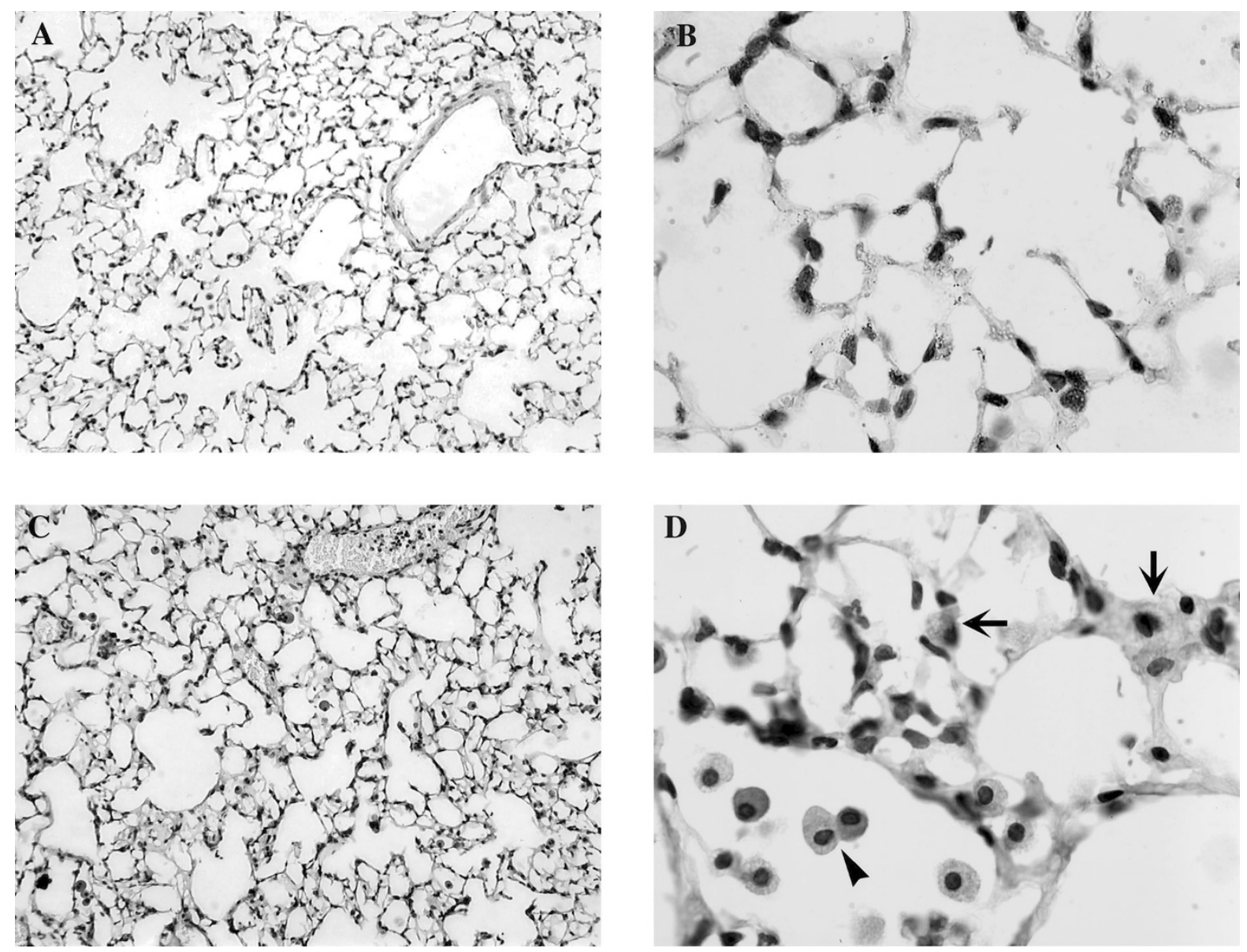

\section{Figure 1.}

Light micrographs of normal (A and B) and acid sphingomyelinase knock-out (ASMKO) (C and D) formalin-fixed lungs from approximately 24-week-old mice after bronchoalveolar lavage $(B A L)$. At low magnification $(\times 20)$ many foamy cells can be seen in the airspaces of the ASMKO lungs $(C)$ and large numbers of inflammatory cells are visible in the lung microvasculature, but otherwise histology is similar to that in normal mouse lungs $(A)$. At higher magnification $(\times 100)$ foamy cells are also seen in the pulmonary interstitium (arrows), as well as in the airspaces (arrowhead) of ASMKO mice (D), and the alveolar walls appear thickened compared with normal mouse lungs (B). Sections were stained with hematoxylin and eosin. 


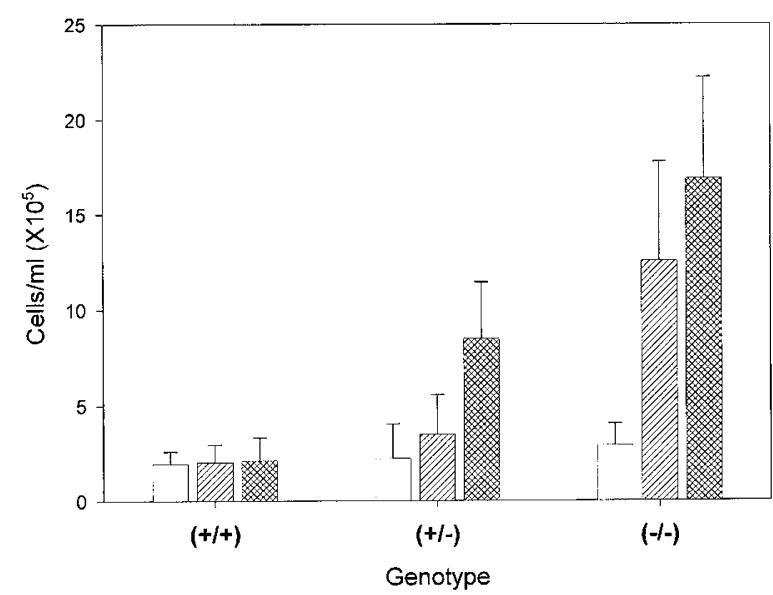

Figure 2.

Total cell numbers in the bronchoalveolar lavage fluid (BALF) of ASMKO mice. There is no change in the total number of cells in the BALF of normal mice with increasing age. (+/-) mice have significantly higher cell numbers compared with normal mice at 22 to 26 weeks of age, whereas in $(-/-)$ mice the total number of cells in the BALF is significantly increased at 10 and at 22 to 26 weeks of age compared with normal mice. Values are shown as mean \pm standard deviation, $n=5$ to 6 mice per group. White bars, 4 weeks; striped bars, 10 weeks; hatched bars, 22 to 26 weeks.

their BALF than both $(+/+, p<0.003)$ and $(+/-, p<$ $0.008)$ mice. The increase in the total number of cells in these mice was even more marked at 22 to 26 weeks of age when they had up to eight times the number of cells as $(+/+, p<0.001)$ mice. At this age the $(+/-)$ mice also had significantly increased total lavage cell numbers compared with the $(+/+, p<$ 0.006) mice.

At all ages observed, $(+/+)$ mouse BALF contained approximately 95\% macrophages, 4\% neutrophils, and the rare multinucleated ( $\mathrm{MN}$ ) macrophage (Table 1). (+/-) mice showed similar cell differentials, although at 22 to 26 weeks there was a slight, but

Table 1. Percentage of Cell Types in the Bronchoalveolar Lavage Fluid of ASMKO Mice

\begin{tabular}{lrrr}
\hline & $(+/+)$ & $(+/-)$ & $(-/-)$ \\
\hline 3-4 weeks old & & & \\
Macrophages & $95.3 \pm 0.5$ & $94.6 \pm 2.3$ & $87.1 \pm 6.0$ \\
MN Macrophages & $0.5 \pm 0.5$ & 0 & $3.0 \pm 2.6$ \\
Neutrophils & $4.3 \pm 0.5$ & $5.4 \pm 2.3$ & $17.5 \pm 3.3$ \\
10 weeks old & & & \\
Macrophages & $94.6 \pm 1.1$ & $96.6 \pm 0.9$ & $86.5 \pm 4.1$ \\
MN Macrophages & $0.8 \pm 0.8$ & $0.8 \pm 0.5$ & $6.0 \pm 1.1$ \\
Neutrophils & $4.6 \pm 1.1$ & $2.7 \pm 1.2$ & $9.3 \pm 5.1$ \\
22-26 weeks old & & & \\
Macrophages & $95.5 \pm 3.1$ & $91.5 \pm 5.1$ & $72.0 \pm 8.9$ \\
MN Macrophages & $1.0 \pm 2.0$ & $2.4 \pm 2.8$ & $11.9 \pm 7.5$ \\
Neutrophils & $3.5 \pm 1.3$ & $6.5 \pm 3.6$ & $16.4 \pm 6.0$ \\
\hline
\end{tabular}

ASMKO, acid sphingomyelinase knock-out.

Bronchoalveolar lavage fluid cell populations in $(-/-)$ ASMKO mice compared to $(+/-)$ and $(+/+)$ littermates. The cell populations do not significantly vary among $(+/+)$ and $(+/-)$ ASMKO mice in the different age groups. In contrast, the $(-/-)$ ASMKO mice have a significantly greater number of multinucleated (MN) macrophages and neutrophils compared with normal mice at 10 and $22-26$ weeks of age. $n=5-6$ mice per group. insignificant, increase in the percentages of MN macrophages and neutrophils present. In (-/-) ASMKO mice the percentage of macrophages composing the total cell population was decreased compared with $(+/+)$ and $(+/-)$ mice, and there was an accompanying increase in neutrophils $(9-17 \%$ vs approximately $4 \%$ in $[+/+]$ mice at 22 to 26 weeks, $p<0.003$ ). However, despite the lower percentages, a higher number of these macrophages were multinucleated by 10 weeks in the $(-/-)$ mice, and $M N$ made up almost $12 \%$ of the total BALF cell population at 6 months of age $(p<0.02$ when compared with $[+/+]$ mice of the same age).

Morphologically, the macrophages from the ASMKO mice appeared to become progressively larger with increasing age (Fig. 3). By 22-26 weeks of age, many macrophages were extremely large and also multinucleated, with some displaying up to five or six small, uniform nuclei when observed under light microscopy. Ultrastructurally, the macrophages were engorged with numerous lamellar vesicles and displayed crystal-like inclusions in the cytoplasm (see Fig. 10).

\section{Sphingomyelin Levels}

The sphingomyelin concentration in the pulmonary airspaces most likely represents accumulated sphingomyelin from the plasma (ie, lipoprotein), together with membrane fragments released from dying macrophages and other lung cells. In (-/-) mice there was a striking increase in the levels of sphingomyelin in the cell-free BALF by 10 weeks of age (Fig. 4, $p<0.007$ compared with $[+/+]$ mice). In 22- to 26-week-old $(-/-)$ mice the sphingomyelin concentration had moderately decreased, but remained significantly elevated compared with age-matched $(+/-)$ and $(+/+)$ mice (10 times higher than in $[+/+]$ mice, $p<0.003$ ).

\section{Chemokine Production}

There were no detectable levels of macrophage inflammatory protein (MIP-2) or macrophage inflammatory protein- $1 \alpha(\mathrm{MIP}-1 \alpha)$ in the BALF from the $(+/+)$ mice; however, both chemokines were significantly elevated in the BALF from (-/-) mice (Fig. 5, A and B; $p<0.05)$. Unstimulated alveolar macrophages cultured from $(-/-)$ mice also released significantly higher levels of both chemokines (Fig. 5, C and D; $p<$ $0.05)$, as detected in the culture supernatants, compared with macrophages from $(+/+)$ mice. Upon stimulation with lipopolysaccharide, both $(-/-)$ and $(+/+)$ macrophages produced significantly higher levels of MIP- $1 \alpha$ and MIP-2 than unstimulated macrophages (Fig. 5D).

Lung sections from 6-month-old (-/-) mice also showed intensive immunostaining of lung macrophages and bronchial epithelial cells using the antibodies to MIP-2 and MIP-1 $\alpha$ (Fig. 6, D and F, respectively), confirming the in vitro results. Less intense staining also was evident in other lung parenchymal cells. There was no detectable staining with these 

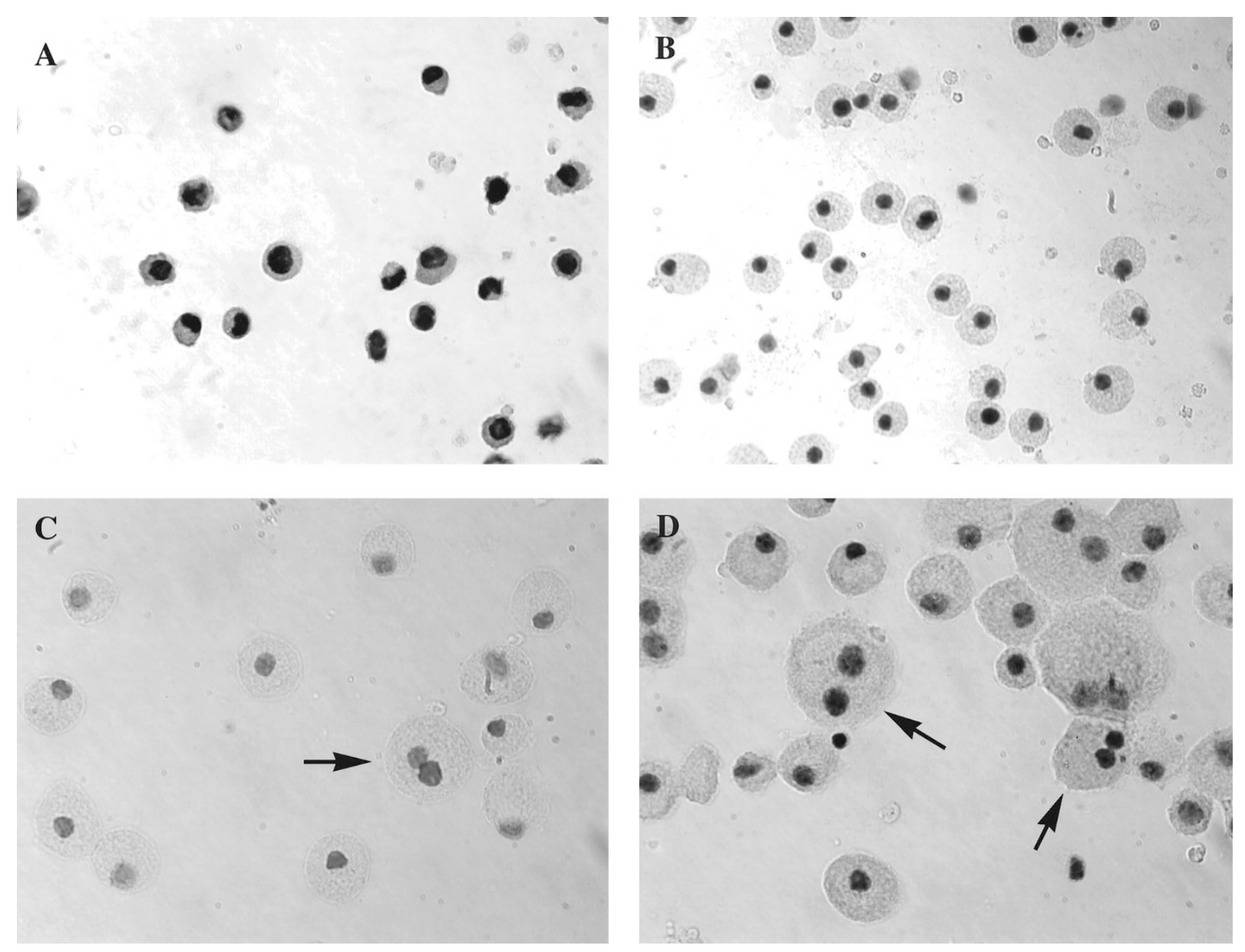

Figure 3.

Cells obtained after BAL of mouse lungs. The majority of cells in the BALF of 4- to 26-week-old normal $(+/+)$ mice are macrophages with large, regular nuclei (A) The BALF of 3- to 4-week-old (-I-) mice already contain distended macrophages with foamy cytoplasm, and small, often multiple nuclei (B). The BALF of 10-week-old mice show similar cytology to the 4-week-old mice (C). At 22 to 26 weeks of age the BALF of $(-/-)$ mice contain very large, often bi- or multinucleated macrophages (arrows) with foamy cytoplasm and increased numbers of neutrophils compared with normal mice (D). Cells are stained with hematoxylin and eosin. Original magnification, $\times 100$

antibodies on lung sections from age-matched $(+/+)$ mice (Fig. 6, C and E, respectively). Negative control sections in which primary antibody was omitted (Fig. $6, A$ and $B$ ), and others in which isotype matched antigoat antibody was used (not shown), showed no staining.

\section{Cell Phenotypes}

Cells obtained by BAL from 6-month-old mice were characterized by immunocytochemical analysis of their surface markers (Fig. 7). In (+/+) mice many, but not all, cells stained to varying degrees with an antiF4/80 antibody and no cells stained with an antiCD11b antibody. In (-/-) mice, however, virtually all of the cells stained with anti-F4/80 antibodies, and many stained very intensely. Also, approximately $5 \%$ of the cells from $(-/-)$ mice stained strongly with the anti-CD11b antibody. Cells from 4-week-old $(+/+)$ and $(-/-)$ mice showed similar staining to that observed with the 6-month-old mice except that there were no anti-CD11b staining cells in $(-/-)$ mice (not shown).

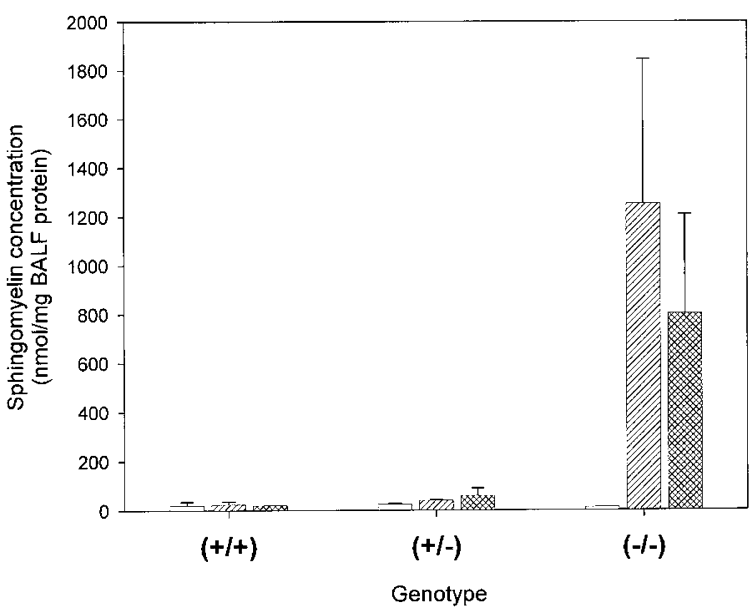

Figure 4.

The sphingomyelin concentration in the BALF is dramatically increased in 10-week-old $(-/-)$ mice and remains significantly elevated in 22- to 26-weekold $(-/-)$ mice compared with age-matched $(+/+)$ and $(+/-)$ mice. Values are shown as mean \pm standard deviation, $n=5$ to 6 mice per group. White bars, 4 weeks; striped bars, 10 weeks; hatched bars, 22 to 26 weeks. 

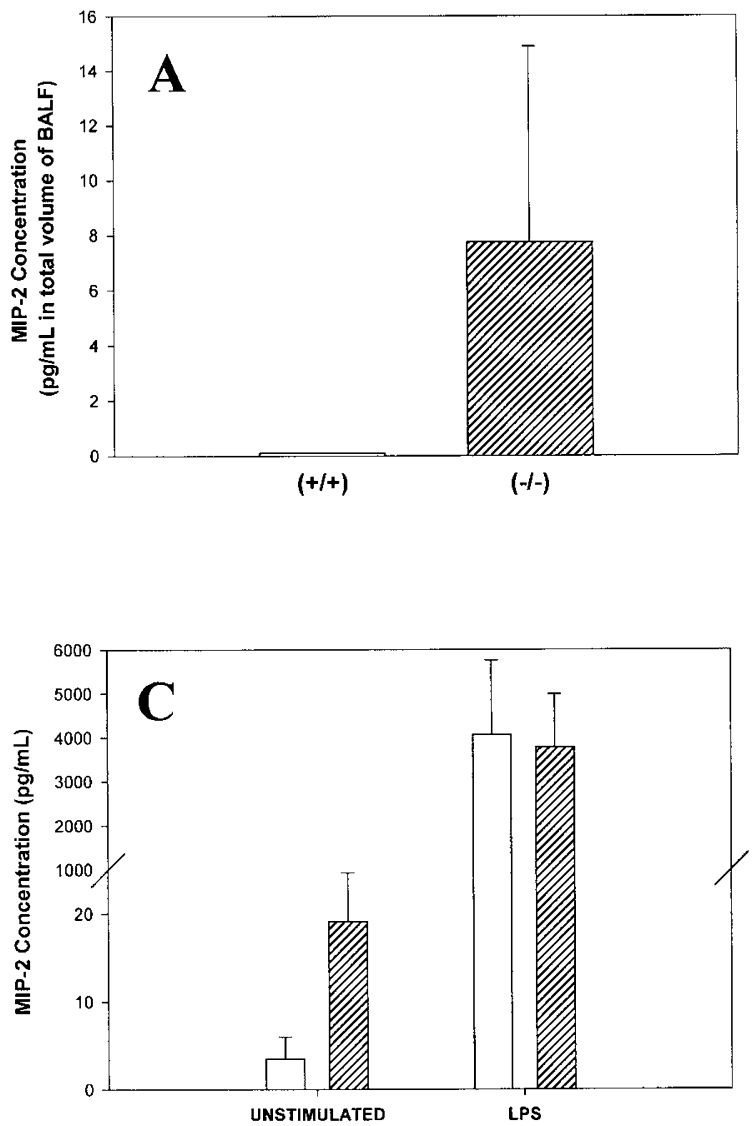
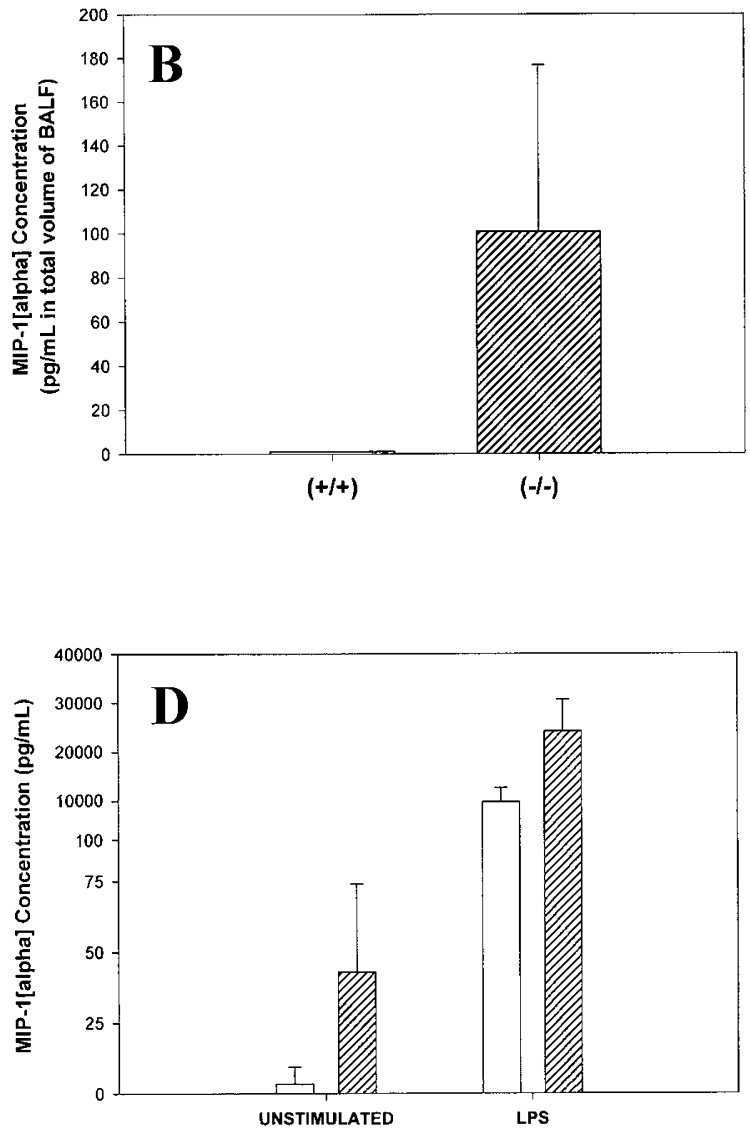

Figure 5 .

Concentrations of the chemokines MIP-2 and MIP-1 $\alpha$ in BALF of ASMKO mice. Elevated levels of both MIP-2 and MIP-1 $\alpha$ were observed by ELISA in the BALF of 6-month-old $(-/-)$ mice compared with age-matched $(+/+)$ mice in which there were no detectable levels of either chemokine (A and $B$, respectively). Unstimulated alveolar macrophages from $(-/-)$ mice also produced significantly higher levels of both MIP-2 and MIP-1 $\alpha$ in culture as compared with $(+/+)$ mice $(C$ and $D$, respectively). Cultured macrophages from (-/-) mice stimulated with LPS also produced higher levels of MIP-1 $\alpha$, but not MIP-2, compared with macrophages from $(+/+)$ mice. White bars, $(+/+)$ mice; striped bars, $(-/-)$ mice. Values are shown as mean \pm standard deviation, $n=4$ to 5 mice per group.

\section{Macrophage Function}

The respiratory burst of BALF cells from 7-month-old ASMKO mice was measured by their ability to produce superoxide anions on stimulation with the soluble mediator phorbol myristate acetate (PMA). Cells from (-/-) mice had significantly lower superoxide production than $(+/+)$ mice (Fig. $8, p<0.008)$. As an indicator of the specificity of the assay, addition of superoxide dismutase to the reaction tubes inhibited production of cytochrome c almost completely (not shown). Addition of recombinant ASM to the culture media resulted in an increase in superoxide production by (-/-) ASMKO cells after 54 hours. The levels were significantly higher than in $(-/-)$ cells not incubated with ASM ( $p<0.006$, Fig. 9), and similar to cells from $(+/+)$ mice cultured for the same length of time (not shown).

\section{Electron Microscopy}

In addition to the enlarged storage macrophages, ultrastructural study of the (-/-) ASMKO mouse lungs revealed the presence of lamellar cytoplasmic inclusions in ciliated cells of the airways, in contrast to nonciliated cells that appeared to be virtually unaffected (Fig. 10, A, C, and E). Endothelial cells and type I alveolar cells also showed abundant lipid storage in the cytoplasm. The type II alveolar cell morphology of $(-/-)$ ASMKO mice appeared to be normal under electron microscopy. Representative electron micrographs of lung tissue from two unrelated adult type B NPD patients are included in this figure for comparison (Fig. 10, B, D, and F), and highlight the similarities between the lung pathology in the human and mouse diseases. Type A NPD lungs also showed similar pathology (not shown). Most of the abnormalities identified in the NPD mice were seen in human lungs, except for the appearance of inclusions in ciliated cells, because no human tracheal or airway sections were available for study.

\section{Discussion}

The data from our study reveals the progressive nature of the pulmonary pathology in ASMKO mice, and highlights the similarities between the ultrastructural lung pathology of this model and the human disease. Several novel functional abnormalities in the NPD lung macrophages also are described. The most prominent 


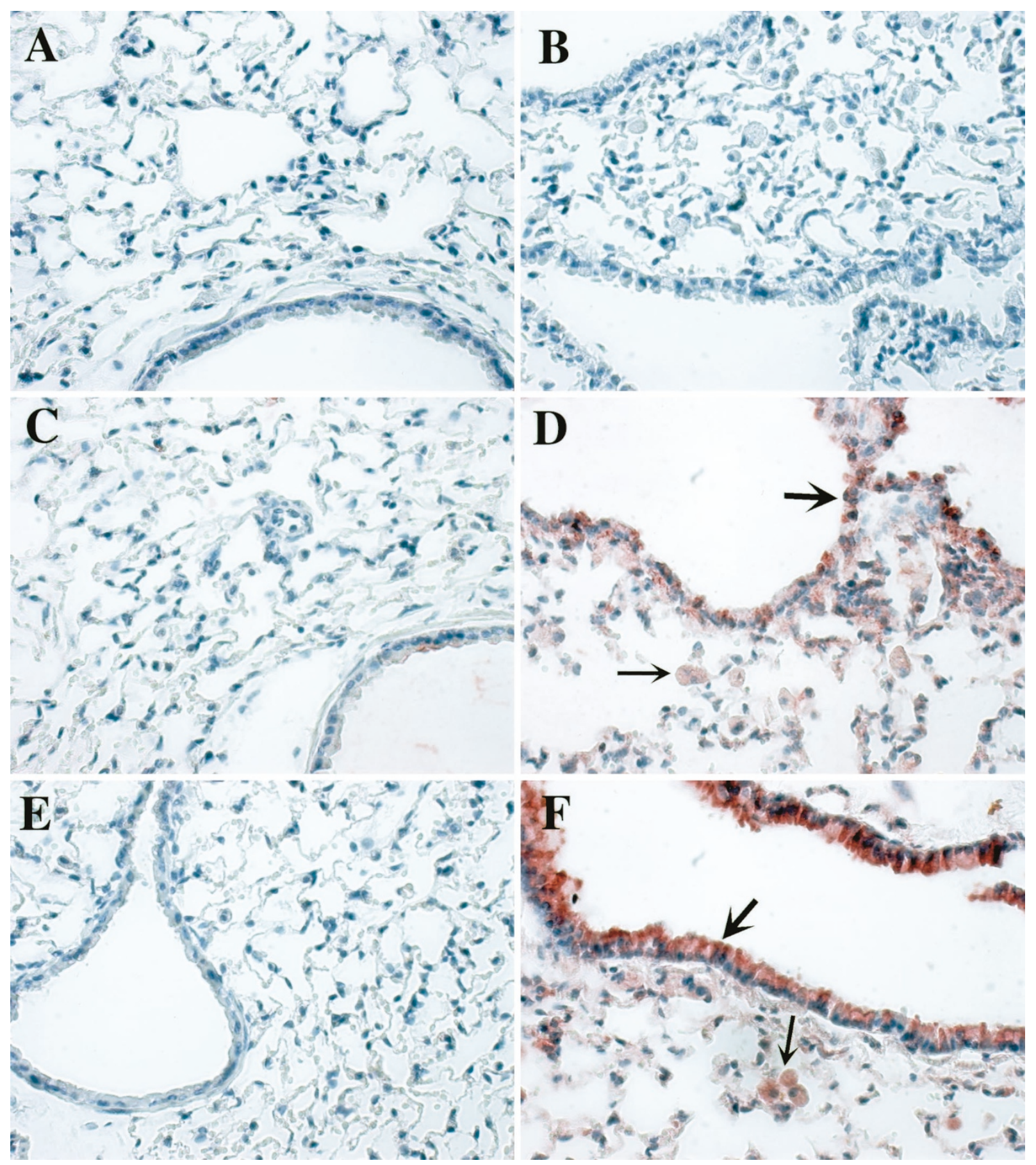

Figure 6 .

Immunohistochemistry with anti-MIP-2 and anti-MIP-1 $\alpha$ antibodies. Lung sections from 6-month-old (-/ - ) mice showed intense staining in bronchial epithelial cells (large arrows) and in macrophages (small arrows) for MIP-2 and MIP-1 $\alpha$ (D and F, respectively). There was no staining for MIP-2 or MIP-1 $\alpha$ on lungs sections from $(+/+)$ mice $(C$ and $E$, respectively). Negative controls $(A$ and $B)$ consisted of lung sections incubated without primary antibody. Original magnification, $\times 40$.

finding in this study was that the total cell population of the pulmonary airspaces and airways (derived from analysis of the BALF), consisting primarily of macrophages, increased dramatically with increasing age in the $(-/-)$ ASMKO mice. Cell numbers in the alveoli began to increase as early as 4 weeks of age, and by 22 weeks of age there was an approximate 8-fold increase in the numbers of alveolar cells in $(-/-)$ ASMKO mice compared with normal mice. By light microscopy, the lungs of mature (-/-) ASMKO mice showed airway lumen and alveolar spaces occluded with numerous "foamy" macrophages, as well as increased cellularity in the alveolar walls caused by the presence of foamy cells in the pulmonary interstitium (Fig. 1). Significantly, we detected no histologic evidence of fibrosis in the ASMKO lungs at any age, a finding consistent with other reports of human type $B$ NPD patients (reviewed in Minai et al, 2000). Also 


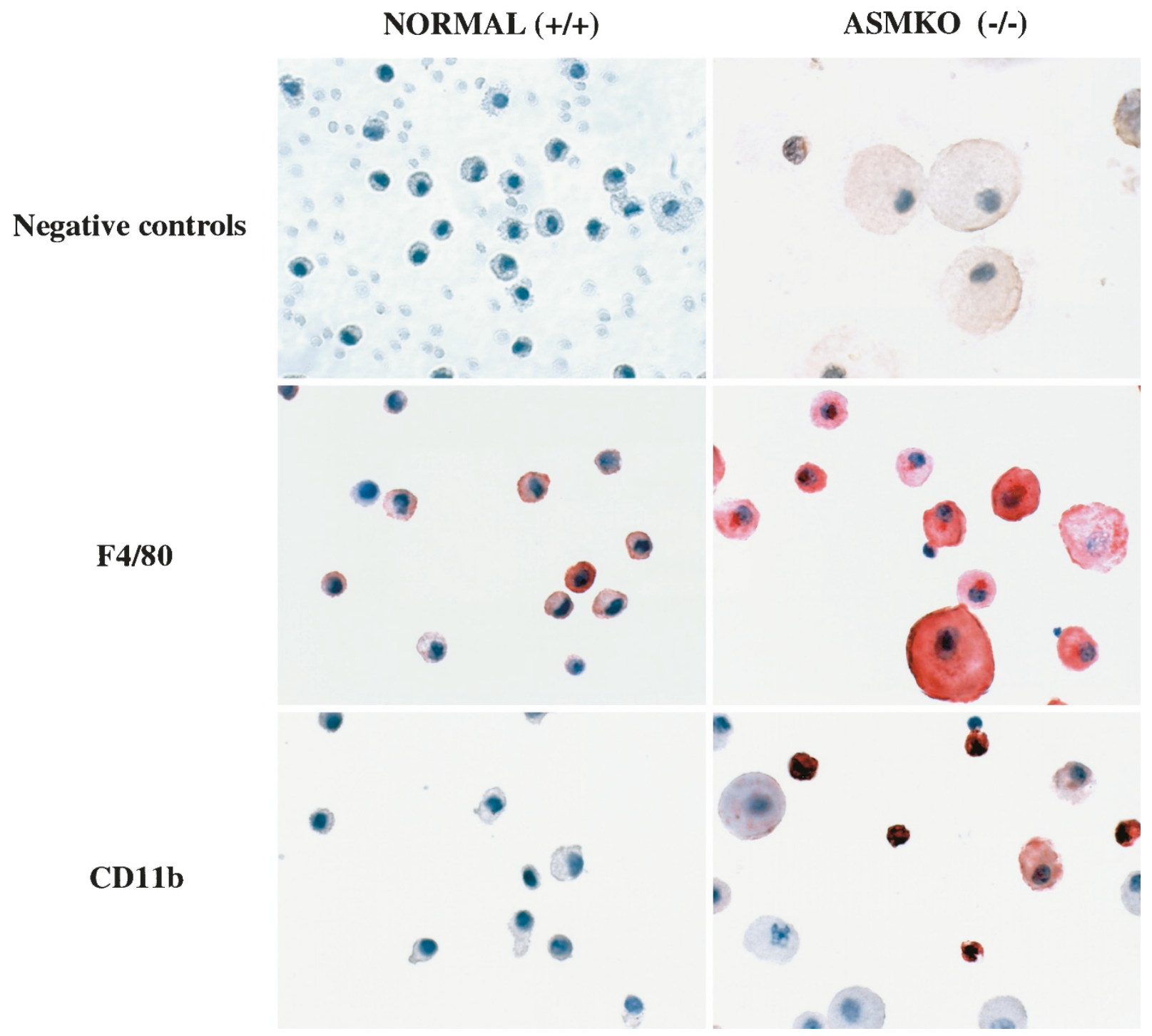

Figure 7.

Macrophage phenotype analysis using immunohistochemistry. Most cells obtained from (-/-) mice by BAL stained intensely with anti-F4/80 and some also stained with anti-CD11b. Cells from (+/+) mice stained much less intensely with anti-F4/80 antibodies and did not stain with anti-CD11b antibodies. Antirat IgG was used as a negative control. Original magnification, $\times 60$.

consistent with some of the reports cited in the above review concerning human patients was evidence of peribronchial edema in some older mice and thickened alveolar walls that were a result of the numerous inflammatory cells present in the interstitium.

An interesting observation not previously reported in NPD or other lipid storage diseases is the rise in the number of neutrophils in the lungs, which suggested a possible increase in the production of neutrophil chemoattractants by lung cells. We have shown that there are elevated levels of the potent neutrophil chemoattractant MIP-2, as well as the monocyte chemoattractant MIP-1 $\alpha$ (Driscoll, 1994), in the BALF of ASMKO mice. Not only is the production of these chemokines elevated in unstimulated cultured $(-/-)$ macrophages, but our immunohistochemical data shows that they are also actively being produced by lung epithelial cells, in particular, the bronchial epithelial cells, in $(-/-)$ mice. The presence of cells positive for CD11b in the BALF of $(-/-)$ mice, which has been shown to be up-regulated on lung cells associated with conditions involving active monocyte infiltration (Orfila et al, 1998; Striz et al, 1993), along with the elevated production of MIP-1 $\alpha$, also suggests that monocyte recruitment is an important contributing factor to the overwhelming number of cells in the lungs. Lack of CD11b staining on cells in young $(-/-)$ mice, which have fewer cells in the lungs, supports this conclusion. $\mathrm{F} 4 / 80$ is a macrophage-specific antigen considered to be a marker of mature macrophages (Leenen et al, 1994). The intense staining of most 6 -month-old (-/-) mouse macrophages with this marker compared with $(+/+)$ mouse cells indicates the presence of more cells in the mature state and suggests a slower turnover rate of these cells. This also may play a role in the elevation of lung cell numbers. The increase in the numbers of neutrophils is particularly interesting because such a chronic inflammatory state is associated 


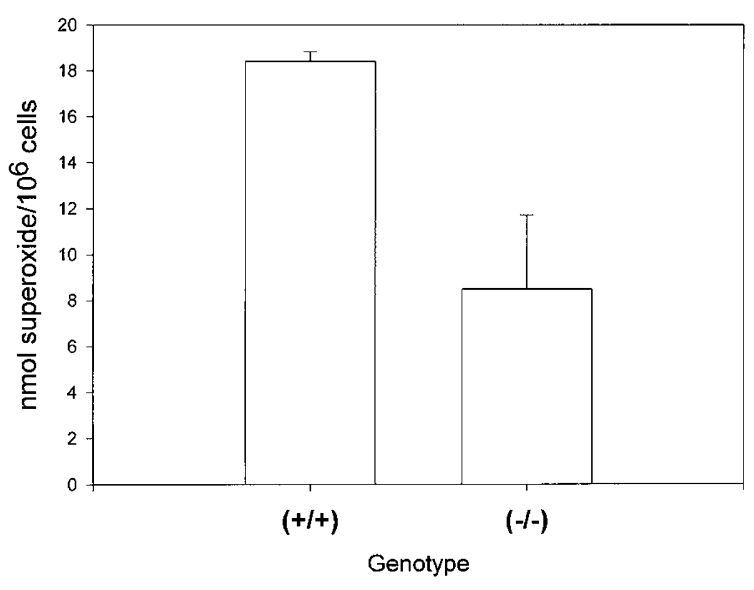

Figure 8.

Superoxide production with phorbol myristate acetate (PMA) stimulation by alveolar cells obtained by BAL from $(+/+)$ and $(-/-)$ ASMKO mice. Mature (approximately 28-week-old) $(-/-)$ mice have almost 2-fold lower superoxide production compared with age-matched normal mice. Values are shown as mean \pm standard deviation, $n=5$ mice per group.

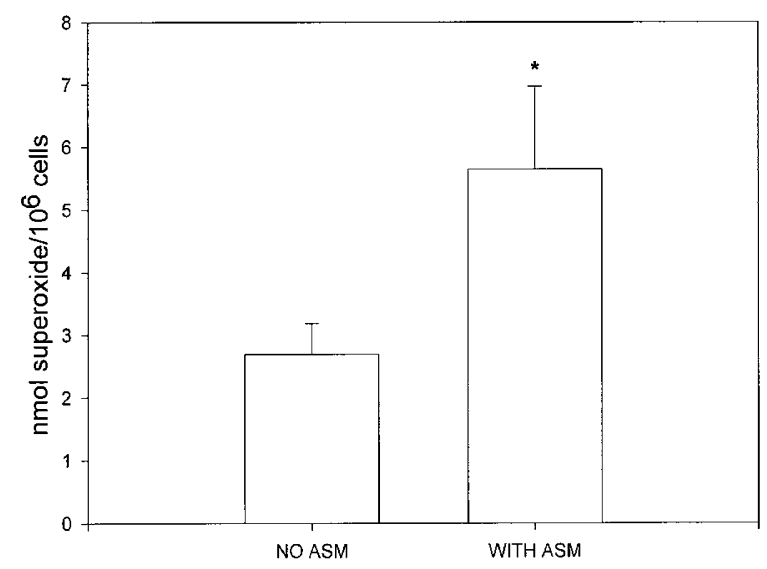

Figure 9.

Superoxide production of (-/-) ASMKO alveolar cells incubated with recombinant acid sphingomyelinase (ASM). Superoxide production by $(-/-)$ ASMKO alveolar cells approximately 54 hours after recombinant human ASM was added to the culture media was significantly higher than cell cultures without ASM. All cells were stimulated with PMA.

with the pathogenesis of emphysema (Selby et al, 1991). In lungs of ASMKO mice that were fixed at constant equal pressure, no histologic evidence of emphysema was observed, even in the oldest group of mice studied (24 weeks). However, there was a suggestion of mildly increased airspace enlargement in localized areas of the lungs removed from two 32-week-old ASMKO mice compared with normal mice. Precise conclusions cannot be drawn from this observation, however, as most ASMKO mice do not survive for more than 28 weeks, precluding study in older mice in which this condition would be relevant. Nevertheless, although it has not previously been reported, it is possible that emphysema may be a contributing factor to lung function decline in older type B NPD patients.

The cause of the increased chemokine production by $(-/-)$ macrophages is currently under investiga- tion, although it is unlikely that it is caused by a generalized state of macrophage activation, as has been proposed in a study of Gaucher disease, another sphingolipid storage disorder with characteristic foam cells (Lichtenstein et al, 1997). In that study using peripheral blood monocytes from Gaucher individuals, the investigators demonstrated increased expression of TNF- $\alpha$ and IL- $1 \beta$, proinflammatory cytokines that can serve as stimuli for the expression of chemokines from a number of cell types (Driscoll, 1994). We found that there was no significant increase in the production of TNF- $\alpha$ or IL- $1 \beta$ by alveolar macrophages from $(-/-)$ mice compared with $(+/+)$ mice (unpublished data), consistent with a previous study that has also shown that the expression of these cytokines is normal in bone marrow-derived monocytes from the ASMKO mice (Manthey, 1998).

Given the fact that the ASMKO mice lack ASM activity, the role of the sphingomyelin-ceramide signal transduction pathway in the regulation of cytokine/ chemokine production merits consideration as a mechanism underlying increased release of MIP-2 and MIP- $1 \alpha$. Ceramide is a product of sphingomyelin hydrolysis and the role of ceramide as a second messenger in various signal transduction pathways is well established (eg, Obeid and Hannun, 1995; Perry and Hannun, 1998). Indeed, ceramide has previously been implicated in TNF- $\alpha$ - and IL- $1 \beta$-mediated activation of NF- $\kappa \mathrm{B}$, which has been extensively studied for its role in the regulation of genes involved in immune and inflammatory responses (Baeuerle and Henkel, 1994). However, the specific role of ASM in NF- $\kappa$ B activation remains unclear (Gamard et al, 1997). NF- $\kappa$ B activation was not altered in ASMKO mouse embryonic fibroblasts (Zumbansen and Stoffel, 1997) or in human Niemann-Pick type A fibroblasts (Gamard et al, 1997) when compared with cells with normal ASM activities. On the other hand, a recent report links the sphingomyelin-ceramide pathway with expression of human interleukin (IL)-8, a functional analog of murine MIP-2, through NF- $\kappa$ B activation in gastric epithelial cells (Masamune et al, 1999). It should be remembered that different cell types (and even the same cells in different compartments) may function through divergent signaling mechanisms, and further analysis of pulmonary cells in the ASMKO mice may help clarify the role of ASM and ceramide signaling in the NPD inflammatory disease process.

In human NPD type B patients the infiltration of foamy cells into the alveoli has been documented in lung biopsy samples (Gogus et al, 1994), but chest radiography has been the most commonly used method to detect the pulmonary manifestations. Respiratory function testing also can be useful in alerting patients and physicians to pulmonary involvement in later stages of the disease, but young NPD patients often present with normal lung function (Ferretti et al, 1996; Niggemann et al, 1994). Characteristics of the BALF have been sparsely documented in incidental cases, and BAL is not a routine procedure in type B NPD diagnosis.

At 6 months of age, when $(-/-)$ ASMKO mice are approaching their demise, not only are the numbers of 

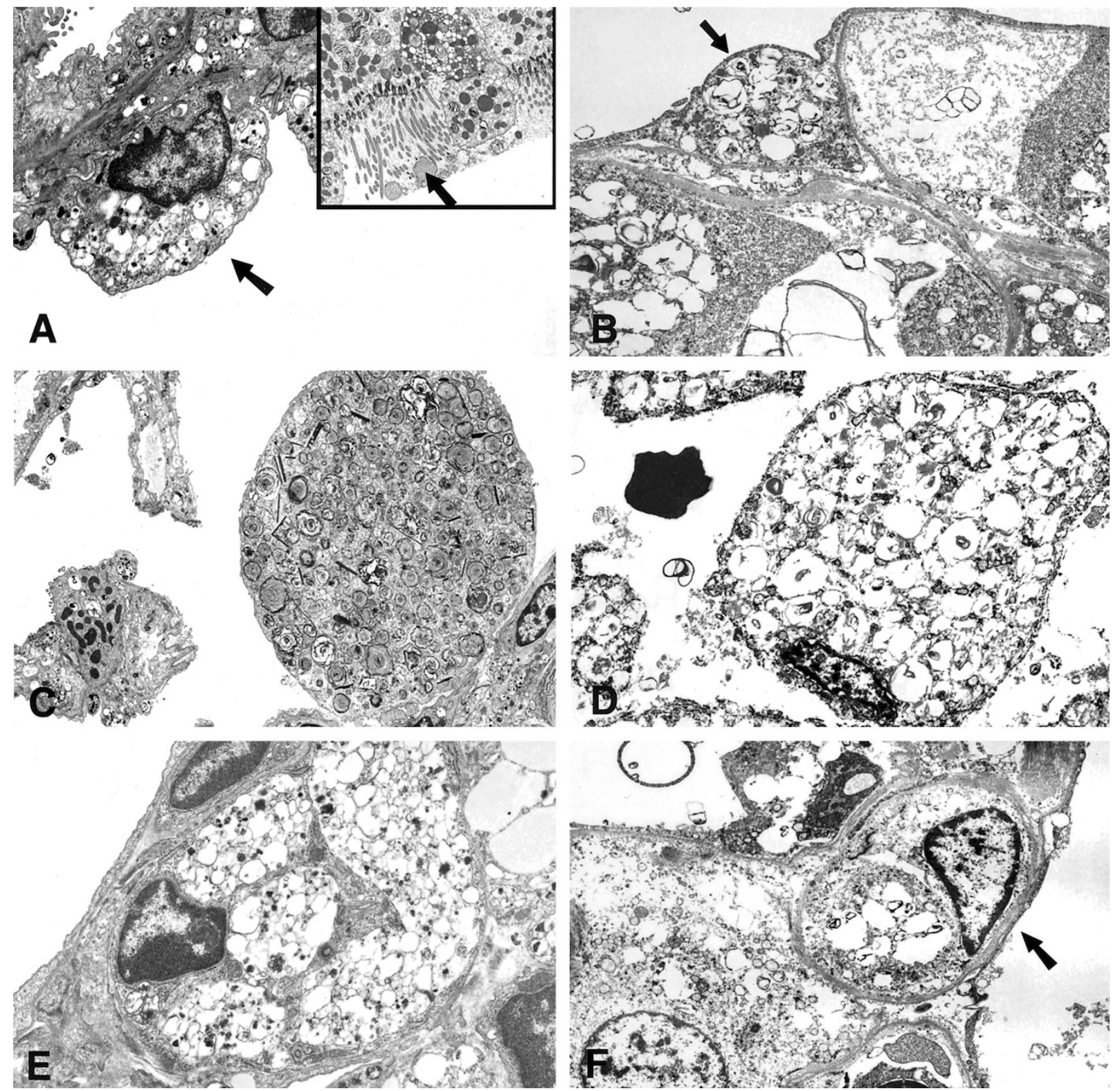

\section{Figure 10.}

Electron microscopy demonstrating similarities between ASMKO mouse and human NPD lungs. Both mouse (A, C, and E) and human (B, D, and F) lungs show type I alveolar cells with cytoplasmic inclusions ( $A$ and $B$, original magnification, $\times 3,300$ ), macrophages with lamellar inclusions ( $C$ and $D$, original magnification, $\times 1,600$ ), and endothelial cells with large amounts of storage material ( $E$ and $F$, original magnification, $\times 5,000$ ). Lungs from mice also show cytoplasmic inclusions within ciliated cells of the bronchi and trachea (A, inset). Arrows point to relevant cell types.

alveolar macrophages abnormal, but their morphology (enlarged size and multiple nuclei) and function are also impaired. Respiratory burst, which is one measure of an inflammatory cell's function, was decreased in the alveolar cells of mature (-/-) ASMKO mice. In these mice, the alveolar cell population consisted predominantly of macrophages that were severely enlarged and often contained several nuclei, as noted above. Such multinucleated macrophages have been observed previously in a number of conditions associated with macrophage phospholipid accumulation. For example, mice disrupted in the granulocytemacrophage colony-stimulating factor receptor pathway, mice lacking surfactant protein $D$, and rats treated with the drug chlorphentermine all showed increased numbers of multinucleated macrophages in their lung lavage fluids (Botas et al, 1998; Dranoff et al, 1994; Reasor et al, 1982).

One possible explanation for the multinucleation phenomenon is that it is a result of cell fusion (Reasor et al, 1982). Indeed it has previously been shown that fusion can occur when monocytes are added to 8-day-old macrophage cultures, a situation somewhat similar to our (-/-) mouse lungs where a considerable number of monocytes are present among a large population of mature macrophages (Most et al, 1997). Interestingly, the authors suggest that this may reflect an attempt by macrophages with reduced intracellular killing capacity, as we have demonstrated in the (-/-) cells, to recover this important function. It is likely that 
the cytoplasmic accumulation of sphingomyelin and/or aberrant production of ceramide in the macrophages are somehow associated with multinucleation and abnormal macrophage function. This is further supported by data showing that addition of ASM to $(-/-)$ BAL cell cultures improves cell function, presumably by hydrolyzing stored intracellular sphingomyelin.

Sphingomyelin is an integral component of pulmonary surfactant, which is composed of phospholipids, neutral lipids, and proteins, and is required to maintain reduced surface tension along the alveoli to facilitate adequate gas exchange during respiration. The percentage of sphingomyelin in surfactant from normal individuals is $2 \%$ to $4 \%$, but has been shown to be increased in individuals with acute lung injury (Bersten et al, 1998; Schmitz and Muller, 1991). The composition of surfactant, including levels of individual components and ratios of various phospholipids, is believed to be important in maintaining normal lung function (Bersten et al, 1998). It is, therefore, likely that in (-/-) ASMKO mice the dramatically increased level of sphingomyelin in the BALF reflects an abnormality in surfactant composition and affects their lung function. Such an analysis of surfactant composition and function in the $(-/-)$ ASMKO mice is currently underway.

Ultrastructural comparison of lung sections from the (-/-) ASMKO mouse and human NPD patients confirms the similarities between the two diseases and provides rationale for the use of the ASMKO mouse described here as an experimental model for investigating the pulmonary pathobiology in this disorder and developing lung-specific therapies. In both mouse and human NPD lungs, the alveolar walls showed no obvious abnormalities other than storage lesions in endothelial cells and type I pneumocytes. Undoubtedly, the most markedly affected cell type was the alveolar macrophage in both mice and humans.

Our overall interpretation of the data presented in this paper is that lung function decline in type B NPD patients is most likely a result of the inflammatory cell infiltration of airways/alveoli and recurring respiratory infections resulting from the dramatic accumulation of storage cells in the lungs. Figure 11 schematically depicts the various processes we believe contribute to inflammatory cell accumulation and abnormal lung physiology. Our data suggests that accumulation of sphingomyelin (and/or repressed production of ceramide) in the pulmonary airspaces is associated with increased cell recruitment into the lungs and abnormal function of the macrophages. It is likely that defects in pulmonary surfactant composition/production are also occurring as a result of sphingomyelin accumulation in NPD mice and patients, and contributing to abnormal lung function. Because macrophage function can be corrected by restoring ASM activity and there is no evidence of damage to the lung architecture (in particular fibrosis) other than inflammatory cell infiltration, therapies directed at increasing sphingomyelin hydrolysis (eg, by enzyme replacement or gene therapy) in lung macrophages might provide a means to prevent pulmonary airspace infiltration and eliminate an environment conducive to infections. Studies are also underway to determine the exact contribution of cell recruitment/turnover to the NPD lung pathobi-

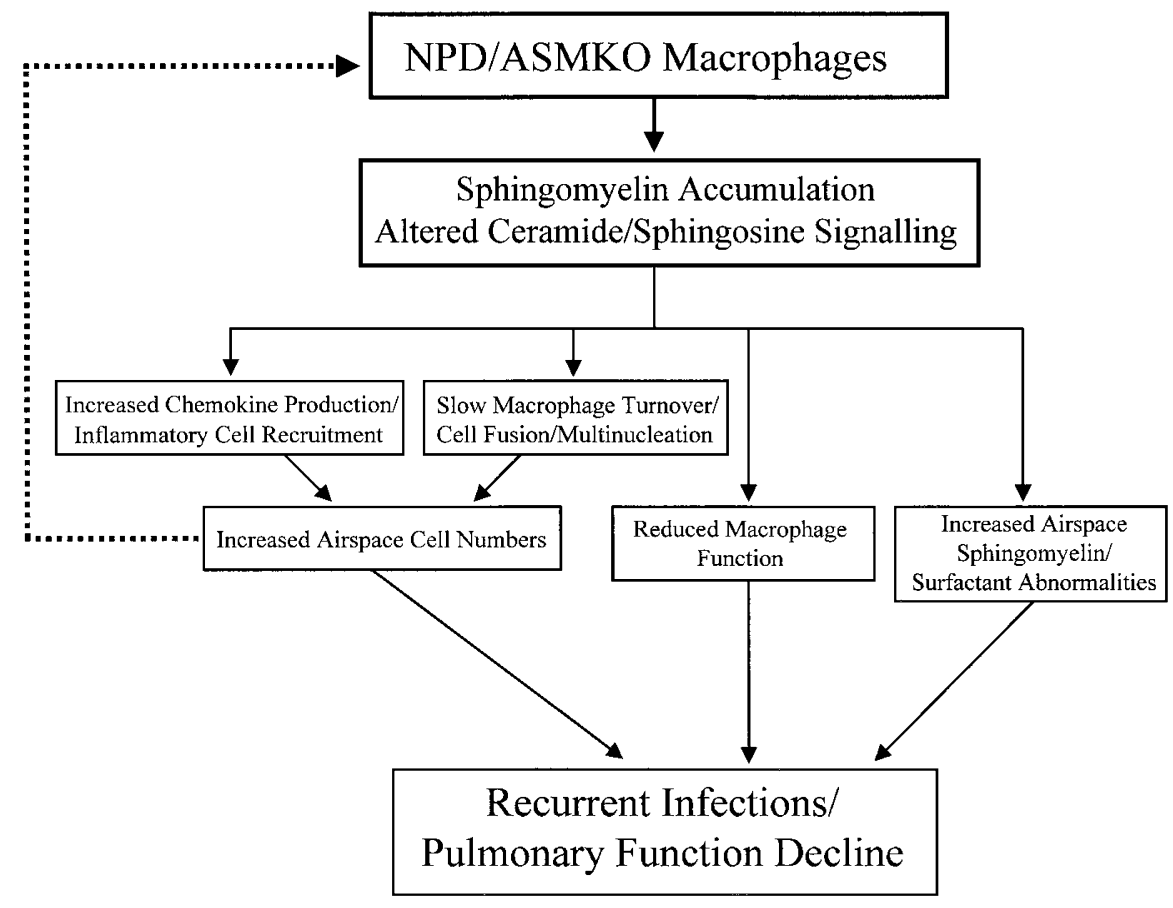

Figure 11.

Schematic depiction of the processes involved in the development of lung pathology in NPD. The accumulation of sphingomyelin and/or altered ceramide signaling in macrophages results in increased chemokine production leading to inflammatory cell recruitment and slow macrophage turnover. Reduced macrophage function also leaves the affected individuals immunologically compromised, and increased airspace sphingomyelin levels may give rise to pulmonary surfactant abnormalities. 
ology, which may lead to the development of alternative therapies, such as modification of chemokine production, for the treatment of pulmonary disease in this disorder.

One final observation from our study is that BALF analysis suggests that $(+/-)$ mice with a partial reduction in ASM activity may also have some lung involvement. At the oldest age studied, (+/-) ASMKO mice had significantly higher levels of cells and sphingomyelin in their airspaces compared with $(+/+)$ mice $(p<$ 0.006 and $p<0.03$, respectively). Further study in heterozygous humans may reveal similar pulmonary involvement in this group.

\section{Materials and Methods}

\section{Animals}

The ASMKO mouse colony was established from heterozygous $(+/-)$ breeding pairs. All mice were housed in a pathogen-free facility according to Institutional Animal Care and Use Committee (IACUC) guidelines. No signs of contamination were reported in the mouse colony and routine histologic evaluation of mouse lungs showed no evidence of infection. Both male and female mice were used for all experiments. $(+/+)$ mice were littermates of ASMKO mice. Genotypes of the mice were identified as previously shown (Horinouchi et al, 1995). (-/-) ASMKO mice have no detectable ASM activity, (+/-) ASMKO mice have variable, but reduced ASM activity, and $(+/+)$ mice have normal levels of ASM activity (Horinouchi et al, 1995).

\section{Experimental Groups}

Lung cell populations and sphingomyelin content were assessed in three groups of $(-/-),(+/-)$, and $(+/+)$ age-matched mice consisting of 4 to 6 animals each. Group 1 mice were approximately 4 weeks of age, Group 2 approximately 10 weeks of age, and Group 3 approximately 22 to 26 weeks of age.

\section{Lung Lavages and Cell Counts}

Mice were killed by halothane overdose and the lungs removed from the chest cavity en bloc, with the trachea intact. An 18-gauge catheter was inserted and tied into the trachea, and the lungs were washed six times by gentle massaging with $0.8 \mathrm{ml}$ of cold normal saline. The BALF was collected in plastic tubes and centrifuged at $500 \mathrm{rpm}$ for 10 minutes. The supernatant was removed and stored at $-20^{\circ} \mathrm{C}$ for later analysis. Lavage fluid recovery was consistently $90 \%$ or higher. The cell pellet was resuspended in $200 \mu \mathrm{l}$ of saline and used for total cell counts with a Neubauer hemacytometer. Ten microliters of the cell suspension was heat-fixed onto slides and stained with hematoxylin and eosin for cell differential analysis. Two hundred cells were counted in one or more fields of view at $60 \times$ magnification.

\section{Sphingomyelin Measurement}

The BALF cell-free supernatants were lyophilized and resuspended in $100 \mu \mathrm{l}$ of $0.2 \%$ Triton $\mathrm{X}-100$ buffer. Sphingomyelin determinations were made using an enzyme-based assay method. Details of this method will be published elsewhere, but briefly lipid extracts were prepared from the BALF and subjected to sequential treatment by neutral sphingomyelinase and diacylglycerol kinase. In this manner the concentration of sphingomyelin can be determined after quantification of the ceramide resulting from sphingomyelinase cleavage.

\section{Electron Microscopy}

Whole mouse lungs were removed from the chest cavity and inflated with $2 \%$ glutaraldehyde in cacodylate buffer and fixed by intratracheal instillation of fixative at $30 \mathrm{~cm}$ pressure for 3 hours. Human formalin-fixed autopsy lung tissue from type B NPD patients were post-fixed with glutaraldehyde and routinely processed for transmission electron microscopy along with the mouse lungs using ethanol dehydration, propylene dioxide, and embedded in Embed 812. One micrometer plastic sections were cut, stained with methylene blue, and observed by light microscopy. Representative areas were chosen for ultrathin sectioning. Ultrathin sections were stained with uranyl acetate and lead citrate and observed with a JEM $100 \mathrm{C} \times \mathrm{TEM}$.

\section{Superoxide Production}

Superoxide release was measured by reduction of cytochrome $\mathrm{c}$ as previously described (Lopez et al, 1986). Briefly, BALF cells from approximately 28week-old mice were harvested as described above, washed, and used immediately. For (-/-) ASMKO mice the cells were approximately $90 \%$ macrophages, similar to $(+/+)$ mice where the cells were approximately $95 \%$ macrophages. The assay was performed in duplicate for a total of five (-/-) ASMKO mice. To acquire sufficient numbers of cells from $(+/+)$ mice, the BALF from seven mice was pooled for each measurement. For each reaction $1 \times 10^{6}$ cells were resuspended in RPMI 1640 medium with 10\% fetal calf serum in polypropylene tubes. The reaction was carried out in a total volume of $1 \mathrm{ml}$. To the suspension was added $1.2 \mathrm{mg} / \mathrm{ml}$ cytochrome c (type IV; Sigma, St. Louis, Missouri) and the cells were stimulated with $100 \mathrm{ng} / \mathrm{ml}$ PMA (Sigma). Superoxide dismutase (SOD, $280 \mathrm{U} / \mathrm{ml}$; Sigma) was added to one tube from each group to confirm specificity of the reaction. The tubes were incubated at $37^{\circ} \mathrm{C}$ for 60 minutes, followed by rapid cooling on ice to stop the reaction. The cells were centrifuged from the suspension at $500 \mathrm{rpm}$ for 10 minutes. The supernatants were removed to plastic disposable cuvettes and the OD of the supernatants was measured at $550 \mathrm{~nm}$. Background absorbance was subtracted and the concentration of superoxide anions in the supernatants was calculated using an extinction coefficient of $29.5 \mathrm{~mm}^{-1}$ (Elliot et al, 1991). 
In one additional experiment, BALF cells were isolated from each 6-month-old (-/-) ASMKO mouse ( $n$ $=4$ ), and aliquoted into three individual polypropylene tubes. Cells were maintained in polypropylene tubes with $1 \mathrm{ml}$ of RPMI 1640 medium supplemented with $10 \%$ fetal calf serum, antibiotics, and fungicide. After approximately 18 hours, purified recombinant ASM $(1.0 \mu \mathrm{g} / \mathrm{ml}$, He et al, 1999) was added to one of the suspension culture tubes from each mouse. Superoxide production was measured as described above approximately 54 hours after addition of the enzyme. Cells were pelleted by centrifugation for 10 minutes at $3,000 \mathrm{rpm}$ and resuspended in fresh RPMI medium for the superoxide production assay. Cells were either unstimulated or stimulated with PMA. For comparison, cells were harvested from $10(+/+)$ mice and pooled. Three suspension cultures of $(+/+)$ cells $\left(1 \times 10^{6}\right.$ cells each) were incubated and analyzed along with the $(-/-)$ mouse cultures.

\section{Cytokine Production}

The lungs of approximately 6-month-old (-/-) mice and age-matched $(+/+)$ mice were lavaged as described above. The cells were pelleted by centrifugation at 800 rpm for 15 minutes, counted, washed once with PBS, and resuspended in RPMI 1640 medium containing $2 \mathrm{~mm}$ L-glutamine, $1 \mathrm{~mm}$ pyruvate, 100 $\mathrm{U} / \mathrm{ml}$ penicillin/streptomycin, and $10 \%$ heatinactivated fetal bovine serum. The cell-free lavage supernatant was stored at $-80^{\circ} \mathrm{C}$ for future analysis of cytokine levels. Cells from each mouse were incubated in duplicate at $37^{\circ} \mathrm{C}$ in 24-well plastic culture plates (Falcon; Becton-Dickinson, Lincoln Park, New Jersey) at a density of $1 \times 10^{6} \mathrm{cells} / \mathrm{ml} /$ well. After 3 hours, nonadherent cells were removed by washing three times with warm PBS and fresh medium was added. Twenty-four to 48 hours after incubation, cells from each mouse were either stimulated with $1 \mu \mathrm{g} / \mathrm{ml}$ lipopolysaccharide (Sigma; E. coli serotype 0111:B4) or not. Medium was collected after 4 hours, aliquoted, and stored at $-80^{\circ} \mathrm{C}$. The concentrations of murine MIP- $1 \alpha$ and murine MIP-2 in the alveolar macrophage culture supernatants and in the cell-free supernatants were determined using commercially available ELISA kits ( $R$ \& D Systems, Minneapolis, Minnesota) according to the manufacturer's recommendations. Samples were diluted as required and measured in duplicate.

\section{Immunohistochemistry}

For use in a standard immunoperoxidase staining procedure formalin-fixed, paraffin-embedded lung sections were deparaffinized in xylene, hydrated through graded alcohols, and washed in deionized water. Cell suspensions were dried onto slides, fixed for 10 minutes in cold acetone, and air-dried. This was followed by quenching of endogenous peroxidase activity with $1 \% \mathrm{H}_{2} \mathrm{O}_{2}$ in methanol and antigen unmasking (for tissue sections) with trypsin incubation at $37^{\circ} \mathrm{C}$. Monoclonal antimouse MIP-2 and MIP- $1 \alpha$ antibodies were purchased from Santa Cruz Biotechnol- ogy (Santa Cruz, California) and antimouse CD11b and F4/80 were purchased from Serotec (Raleigh, North Carolina). Primary antibodies were incubated overnight at $4^{\circ} \mathrm{C}$. AEC was used as the substrate for the peroxidase reaction. Slides were counterstained with Mayer's hematoxylin.

\section{Acknowledgement}

We thank Milan Elleder of the Institute for Inherited Metabolic Diseases, Charles University, Prague, Czechoslovakia, for his assistance with this work and thoughtful comments.

\section{References}

Baeuerle PA and Henkel T (1994). Function and activation of NF-kappa B in the immune system. Annu Rev Immunol 12:141-179.

Bersten AD, Doyle IR, Davidson KG, Barr HA, Nicholas TE, and Kermeen F (1998). Surfactant composition reflects lung overinflation and arterial oxygenation in patients with acute lung injury. Eur Respir J 12:301-308.

Botas C, Poulain F, Akiyama J, Brown C, Allen L, Goerke J, Clements J, Carlson E, Gillespie A-M, Epstein C, and Hawgood $S$ (1998). Altered surfactant homeostasis and alveolar type II cell morphology in mice lacking surfactant protein D. Proc Natl Acad Sci USA 95:11869-11874.

Bouziani A, Cheikh R, Rejeb AB, Khedhiri F, Hamadi FB, Gabsi S, Mustapha MB, Kirane MB, and Hassine KB (1990). Computed tomography and cytology of broncho-alveolar lavage liquid in a case of Niemann-Pick disease: The physionomy of the disease in Tunisia. Rev Mal Respir 7:267-271.

Dranoff G, Crawford AD, Sadelain M, Ream B, Rashid A, Bronson RT, Dickersin GR, Bachurski CJ, Mark EL, Whitsett JA, and Mulligan RC (1994). Involvement of granulocytemacrophage colony-stimulating factor in pulmonary homeostasis. Science 264:713-716.

Driscoll KE (1994). Macrophage inflammatory proteins: Biology and role in pulmonary inflammation. Exp Lung Res 20:473-490.

Elliot MJ, Strasser A, and Metcalf D (1991). Selective upregulation of macrophage function in granulocytemacrophage colony-stimulating factor transgenic mice. J Immunol 9:2957-2963.

Ferretti G., Lantuejoul S, Brambilla E, and Coulomb M (1996). Pulmonary involvement in Niemann-Pick disease subtype B: CT findings. J Comput Assist Tomogr 20:990-992.

Gamard CJ, Dbaibo GS, Liu B, Obeid LM, and Hannun YA (1997). Selective involvement of ceramide in cytokineinduced apoptosis. J Biol Chem 272:16474-16481.

Gerbaux J, Grunber J, Baculard A, Tournier G, BocconGibod L, and Cohen-Solal D (1971). Prolonged form of Niemann-Pick disease with only respiratory manifestation. Ann Pediatr 18:366-371.

Gogus S, Gocmen A, Kocak N, Kiper N, Kucukali T, Yuce A, and Buyukpamukcu N (1994). Lipidosis with sea-blue histiocytes: Report of two siblings with lung involvement. Turk J Pediatr 36:139-144. 
He X, Miranda SRP, Xiong X, Dagan A, Gatt S, and Schuchman EH (1999). Characterization of human acid sphingomyelinase purified from the media of overexpressing Chinese hamster ovary cells. Biochim Biophys Acta 1432:251-264.

Horinouchi K, Erlich S, Perl DP, Ferlinz K, Bisgaier CL, Sandhoff K, Desnick RJ, Stewart CL, and Schuchman EH (1995). Acid sphingomyelinase deficient mice: A model of types A and B Niemann-Pick disease. Nat Genet 10:288293.

Kovesi TA, Lee J, Shuckett B, Clarke JTR, Callahan JW, and Phillips MJ (1996). Pulmonary infiltration in Niemann-Pick disease type C. J Inherit Metab Dis 19:792-793.

Kuemmel TA, Thiele J, Schroeder R, and Stoffel W (1997). Pathology of visceral organs and bone marrow in an acid sphingomyelinase deficient knock-out mouse line, mimicking human Niemann-Pick disease Type A. Pathol Res Pract 193:663-671.

Leenen PJ, de Bruijn MF, Voerman JS, Campbell PA, and van Ewijk W (1994). Markers of mouse macrophage development detected by monoclonal antibodies. J Immunol Methods 174:5-19.

Lever AML and Ryder JB (1983). Cor pulmonale in an adult secondary to Niemann-Pick disease. Thorax 38:873-874.

Lichtenstein M, Zimran A, and Horowitz M (1997). Cytokine mRNA in Gaucher disease. Blood Clells Mol Dis 23:395-401.

Lopez AF, Williamson DJ, Gamble JR, Begley CG, Harlan JM, Klebanoff SJ, Waltersdorph A, Wong G, Clark SC, and Vadas MA (1986). Recombinant human granulocyte-macrophage colony-stimulating factor stimulates in vitro mature human neutrophil and eosinophil function, surface receptor expression and survival. J Clin Invest 78:1220-1224.

Manthey CL and Schuchman EH (1998). Acid sphingomyelinase-derived ceramide is not required for inflammatory cytokine signalling in murine macrophages. Cytokine 10:654-661.

Masamune A, Shimosegawa T, Masamune O, Mukaida N, Koizumi M, and Toyota T (1999). Helicobacter pyloridependent ceramide production may mediate increased interleukin 8 expression in human gastric cancer cell lines. Gastroenterology 116:1330-1341.

Minai OA, Sullivan EJ, and Stoller JK (2000). Pulmonary involvement in Niemann-Pick disease: Case report and literature review. Respir Med 94:1241-1251.

Most J, Spotl L, Mayr G, Gasser A, Sarti A, and Dierich MP (1997). Formation of multinucleated giant cells in vitro is dependent on the stage of monocyte to macrophage maturation. Blood 89:662-671.
Niggemann B, Rebien W, Rahn W, and Wahn U (1994). Asymptomatic pulmonary involvement in 2 children with Niemann-Pick disease type B. Respiration 61:55-57.

Obeid LM and YA Hannun (1995). Ceramide: A stress signal and mediator of growth suppression and apoptosis. J Cell Biochem 58:191-198.

Orfila C, Lepert JC, Gossart S, Frisach MF, Cambon C, and Pipy B (1998). Immunocytochemical characterization of lung macrophage surface phenotypes and expression of cytokines in acute experimental silicosis in mice. Histochem $\mathrm{J}$ 30:857-867.

Otterbach B and Stoffel W (1995). Acid sphingomyelinasedeficient mice mimic the neurovisceral form of human lysosomal storage disease (Niemann-Pick disease). Cell 81: 1053-1061.

Perry DK and Hannun YA (1998). The role of ceramide in cell signalling. Biochim Biophys Acta 1436:233-243.

Reasor MJ, Massey CA, Koshut RA, and Castranova V (1982). Multinucleation in alveolar macrophages from rats treated with chlorphentermine. Lab Invest 46:224-230.

Schmitz G and Muller G (1991). Structure and function of lamellar bodies: Lipid-protein complexes involved in storage and secretion of cellular lipids. J Lipid Res 32:1539-1570.

Schuchman EH and Desnick RJ (2001). Niemann-Pick disease types A and B: Acid sphingomyelinase deficiencies. In: Schriver CR, Beaudet AL, Sly WS, and Valle D, editors. The metabolic and molecular bases of inherited disease, vol 3. New York: McGraw-Hill Inc., 3589-3610.

Selby C, Drost E, Lannan S, Wraith K, and MacNee W (1991). $\mathrm{PMN}$ retention in the lungs of patients with chronic obstructive pulmonary disease. Am Rev Respir Dis 1359-1364.

Striz I, Wang YM, Svarcova L, Trnka C, and Costabel U (1993). The phenotype of alveolar macrophages and its correlation with immune cells in bronchoalveolar lavage. Eur Respir J 6:1287-1294.

Volk BW, Adachi M, and Schneck L (1972). Pathology of sphingolipidoses. Semin Hematol 9:327-329.

Zumbansen M and Stoffel W (1997). Tumor necrosis factor $\alpha$ activates NF- $\kappa \mathrm{B}$ in acid sphingomyelinase-deficient mouse embryonic fibroblasts. J Biol Chem 272:10904-10909. 